\title{
The erythrocyte sedimentation rate in syphilis
}

\author{
W. FOWLER \\ General Hospital, Birmingham
}

\section{Summary}

The erythrocyte sedimentation rate was studied in 520 men and 202 women with syphilis. It was raised in 66.6 per cent. of sero-negative primary cases, 80 per cent. of sero-positive cases, roo per cent. of secondary cases, 80 per cent. of early latent cases, and 73.9 per cent. of late latent cases. It was also raised in sixteen out of seventeen cases of neurosyphilis and in all eleven cases of cardiovascular syphilis.

It was concluded that the ESR had little place in the management of syphilis in general, but could be helpful in the post-treatment follow-up of late syphilis.

\section{Introduction}

The effect syphilis might have on the erythrocyte sedimentation rate (ESR) was considered briefly in 1962 (Fowler, 1962). The investigations upon which that paper was based had started 2 years previously, have continued since, and are reported in the present paper.

The purpose of the study was to determine what changes, if any, occurred in the ESR in the various stages of syphilis. A particular aim of the study was to find out if any such changes had a place in the management of latent syphilis, cardiovascular syphilis, and other forms of the disease in which the clinical signs do not correlate well with the activity of the infection.

\section{Method}

The aim was to measure the ESR (Westergren) immediately before treatment started, daily during treatment, and if necessary, at intervals after treatment. A rate of $8 \mathrm{~mm}$. in one hour was to be regarded as the upper limit of normal for the ESR in males and $13 \mathrm{~mm} / 1 \mathrm{st} \mathrm{hr}$ in females. These are above the normal limits given by Horrobin (1968) for healthy young men and women (1 to

Received for publication January 1, 1976

Address for reprints: Dr W. Fowler, M.D., General Hospital, Steelhouse Lane, Birmingham B4 $6 \mathrm{NH}$

Based on a paper read at the Jubilee Meeting of the MSSVD, Glasgow, 1972
$3 \mathrm{~mm}$ and 4 to $7 \mathrm{~mm}$ respectively) but were adopted to ensure that there could be no question whether or not an ESR was raised.

Considerable care was taken during the general examination of these patients to investigate whether any other condition which might affect the ESR was present. Cases of cardiovascular and neurosyphilis usually had in-patient treatment, mainly with benzyl penicillin in a dosage of at least 1 m.u. daily. All other types of syphilis received outpatient treatment with procaine penicillin $(600,000$ or 900,000 units) daily for 14 days followed by benzathine penicillin $1.2 \mathrm{~m}$.u. bi-weekly for 2 weeks. (Patients allergic to penicillin were excluded from the study.)

Since the study began, 1,733 new cases of syphilis (1,091 male cases and 642 female cases) have been treated in the clinic but sufficient data for inclusion in this report were obtained in only 520 men and 202 women (of whom 55 were pregnant). As pregnancy results in an increase in the ESR (Hytten and Lind, 1973), the 55 pregnant women are considered separately. The forms of syphilis in the 520 male cases and in the other 147 female cases are shown in Table I.

TABLE I Types of syphilis in patients included in series

\begin{tabular}{|c|c|c|c|}
\hline \multirow{2}{*}{ Stage of syphilis } & \multicolumn{2}{|l|}{$\operatorname{Sex}$} & \multirow{2}{*}{ Total cases } \\
\hline & Male & Female & \\
\hline Seronegative primary & 20 & 1 & 21 \\
\hline Seropositive primary & 164 & 27 & 191 \\
\hline Secondary & 104 & 46 & 150 \\
\hline Early latent & 42 & 28 & 70 \\
\hline Late latent & $\overline{166}$ & 41 & 207 \\
\hline Cardiovascular & 10 & 1 & 11 \\
\hline Neurosyphilis & 14 & 3 & 17 \\
\hline$\overline{\text { Total }}$ & 520 & $\overline{147}$ & $\overline{667}$ \\
\hline
\end{tabular}

\section{Results}

456 ( 68.3 per cent.) of the 667 cases in Table I were found to have an increased ESR when examined initially. The percentage of cases presenting this feature increased from the sero-negative primary to the secondary stage of the disease, then decreased in the early latent stage and showed a further decrease in the late latent stage. Even here the ESR was 
raised when the patient first attended in 57.9 per cent. of cases, as it was in fifteen of the seventeen cases of neurosyphilis and in every case of cardiovascular syphilis (Table II). It is worthwhile noting that the ESR remains high in cardiac failure due to active syphilitic aortitis.

The ESRs covered a wide range at every stage of the disease. The highest individual rates occurred in secondary syphilis and the highest average rates in cardiovascular syphilis. However, it is important to draw attention to the high rates reached at times in late latent syphilis (Table II).

\section{Occult Herxheimer reaction}

In 459 (68.89 per cent.) of the 667 cases there was an increase in the ESR soon after treatment started. The term 'occult Herxheimer' reaction is suggested for this increase as it occurred frequently in the absence of any clinical signs of an Herxheimer reaction. This occult Herxheimer reaction occurred in 97 cases in which the ESR was normal before treatment started (Table III), but was not observed in some cases in which the ESR was raised initially. The percentage of cases of this phenomenon increased with the duration of the infection up to the secondary stage, decreased slightly in the early latent stage and decreased much more in the late latent stage. However, even at this stage, the occult Herxheimer reaction was recorded in 58.4 per cent. of cases. It was also present in nine of the eleven cases of cardiovascular syphilis and twelve of the seventeen cases of neurosyphilis (Table III).

The amount of increase in the ESR varied widely at each stage of the disease, and on average, was most pronounced in secondary syphilis. However, it is interesting to note that the largest increase in the ESR after treatment occurred in a case of late latent syphilis (Table III).

The time taken for the ESR to reach its highest level after treatment was started was related to the stage of the disease. In primary and secondary syphilis the peak was usually reached by the third day of treatment, whereas in late syphilis of all types the increase developed more slowly and in some cases was not completed until the fifth day.

\section{Antibody titre and ESR}

The possibility was explored of a relationship between antibody titre and the ESR. No definite relationship was found nor did there appear to be any association

TABLE II Initial ESR

\begin{tabular}{|c|c|c|c|c|c|}
\hline \multirow{2}{*}{ Stage of syphilis } & \multirow{2}{*}{ No. of cases } & \multicolumn{2}{|l|}{$E S R$} & \multirow{2}{*}{ Range (mm./1st hr) } & \multirow{2}{*}{ Mean rate $(\mathrm{mm} . / 1 \mathrm{st} \mathrm{hr})$} \\
\hline & & Normal & Raised & & \\
\hline Seronegative primary & 21 & 12 & 9 & $9-21$ & 10 \\
\hline Seropositive primary & 191 & 62 & 129 & $10-102$ & 21 \\
\hline Secondary & 150 & 24 & 126 & $9-143$ & 35 \\
\hline Early latent & 70 & 22 & 48 & $10-80$ & 15 \\
\hline Late latent & 207 & 87 & 120 & $9-90$ & 26 \\
\hline Cardiovascular & 11 & - & 11 & $20-95$ & 45 \\
\hline Neurosyphilis & 17 & 2 & 15 & $11-52$ & 24 \\
\hline Total & 667 & 209 & 458 & & \\
\hline
\end{tabular}

TABLE II I Effect of treatment on ESR: occult Herxheimer reaction

\begin{tabular}{|c|c|c|c|c|}
\hline Stage of syphilis & No. of cases & $\begin{array}{l}\text { No. with occult Herxheimer } \\
\text { reaction }\end{array}$ & $\begin{array}{l}\text { Range of increase of ESR } \\
(\mathrm{mm} . / 1 \mathrm{st} \mathrm{hr})\end{array}$ & $\begin{array}{l}\text { Mean increase } \\
(\mathrm{mm} . / 1 \mathrm{st} \mathrm{hr})\end{array}$ \\
\hline Seronegative primary & 21 & $10(5)^{\star}$ & $11-30$ & 13 \\
\hline Secondary & 150 & $137(24)^{\star}$ & $8-45$ & 18 \\
\hline Early latent & 70 & $36(10)^{\star}$ & $8-11$ & 16 \\
\hline Cardiovascular & 11 & $9(-)^{\star}$ & $10-33$ & 16 \\
\hline Neurosyphilis & 17 & $12(1)^{\star}$ & $5-44$ & 13 \\
\hline Total & 667 & $459(97)^{\star}$ & & \\
\hline
\end{tabular}

*The numbers in brackets show the cases in which the ESR was normal before treatment started 
between the antibody titre and the amount by which the ESR rose in the occult Herxheimer reaction.

Total number of cases with raised ESR

Table IV shows the total number of cases in which the ESR was raised, i.e. those in which it was raised before treatment is given together with those in which it was within normal limits initially but rose early in the treatment period.

TABLE IV Percentage of cases with raised ESR

\begin{tabular}{|c|c|c|c|}
\hline \multirow{2}{*}{ Stage of syphilis } & \multirow{2}{*}{ Total cases $\star$} & \multicolumn{2}{|c|}{ ESR raised } \\
\hline & & No. & Per cent. \\
\hline Seronegative primary & 21 & 14 & $66 \cdot 6$ \\
\hline Seropositive primary & 191 & 153 & 80 \\
\hline Secondary syphilis & 150 & 150 & 100 \\
\hline Early latent & 70 & 58 & $80 \cdot 2$ \\
\hline Late latent & 207 & 153 & $73 \cdot 9$ \\
\hline Cardiovascular & 11 & 11 & 100 \\
\hline Neurosyphilis & 17 & 16 & $94 \cdot 1$ \\
\hline
\end{tabular}

* Cases with raised ESR before treatment and cases in which it rose after the start of treatment

Time taken for the ESR to return to normal

Generally speaking, the earlier the infection, the sooner the ESR returned to normal after treatment. This is clearly shown in Table V, but attention must be drawn to the long time the ESR can take to return to normal in cases of late syphilis and, in particular, in cases of cardiovascular syphilis.

Late rise in ESR

Between the 9th and 15th day of treatment, but usually on the 10th or 11th day, there was an increase, sometimes substantial, in the ESR in about 25 per cent. of cases. This increase, which disappeared within a few days, had no relationship to the stage of the infection and occured whether or not the ESR had been normal, had been elevated and returned to normal, or was still raised.

\section{Pregnancy and the occult Herxheimer reaction}

The number of cases in pregnant women in each stage of syphilis is shown in Table VI. The progressive rise in the ESR in pregnancy ranges from 30 to $98 \mathrm{~mm} / 1 \mathrm{st} \mathrm{hr}$ (Hythen and Lind, 1973). As these patients in our series had been pregnant for at least 4 months, the level of the ESR before treatment is not recorded. The number of cases in which an occult Herxheimer reaction occurred is shown in Table VI. It is important to note that the ESR pattern after treatment differs from that described above in that the decline in ESR usually ceased before the initial level had been reached and that the rate then gradually increased again as in normal pregnancy.

TABLE VI Occult Herxheimer reaction in pregnancy

\begin{tabular}{|c|c|c|c|c|}
\hline \multirow{2}{*}{$\begin{array}{l}\text { Stage of } \\
\text { syphilis }\end{array}$} & \multirow{2}{*}{$\begin{array}{l}\text { No. of } \\
\text { cases }\end{array}$} & \multirow{2}{*}{$\begin{array}{l}\text { No. with } \\
\text { occult } \\
\text { Herxheimer } \\
\text { reaction }\end{array}$} & \multicolumn{2}{|c|}{ Increase in ESR $(\mathrm{mm} . / 1 \mathrm{st} \mathrm{hr})$} \\
\hline & & & Range & Mean \\
\hline $\begin{array}{l}\text { Seropositive } \\
\text { primary }\end{array}$ & 9 & 9 & $5-35$ & 18 \\
\hline Secondary & 6 & 5 & $14-64$ & 21 \\
\hline Early latent & 18 & 16 & $6-57$ & 26 \\
\hline Late latent & 22 & 15 & $7-34$ & 16 \\
\hline
\end{tabular}

In one case of secondary syphilis, two cases of early latent syphilis, and two cases of late latent syphilis, an occult Herxheimer reaction did not occur. Instead, the ESR gradually decreased over a period of 3 to 4 weeks and then resumed the normal trend. In the remaining five cases of latent syphilis, treatment had no apparent effect upon the ESR.

Other conditions affecting the ESR

Early in the study it was difficult to accept that the very high ESRs found at times, especially in late

TABLE V Time taken for ESR to return to normal

\begin{tabular}{|c|c|c|c|c|c|c|c|c|c|c|c|c|c|}
\hline \multirow{2}{*}{ Type of syphilis } & \multirow{2}{*}{$\begin{array}{l}\text { No. of cases with } \\
\text { raised ESR }\end{array}$} & \multicolumn{12}{|c|}{ Length of time taken for ESR to return to normal (days) } \\
\hline & & No. & Per cent. & No. & Per cent. & No. & Per cent. & No. & Per cent. & No. & Per cent. & No. & Per cent. \\
\hline Seronegative primary & 14 & 8 & & 6 & & & & & & & & & \\
\hline Seropositive primary & 153 & 46 & 30 & 63 & $41 \cdot 1$ & 39 & $25 \cdot 6$ & 4 & $2 \cdot 6$ & 1 & $0 \cdot 6$ & & \\
\hline Early latent & 58 & 9 & $15 \cdot 5$ & 15 & $25 \cdot 8$ & 19 & $32 \cdot 7$ & 12 & $20 \cdot 6$ & 3 & $5 \cdot 1$ & & \\
\hline Late latent & 153 & 14 & $9 \cdot 1$ & 30 & $19 \cdot 6$ & 53 & $34 \cdot 6$ & 40 & $26 \cdot 1$ & 12 & (7.8) & 4 & $2 \cdot 6$ \\
\hline Cardiovascular & 11 & & & & & & & 1 & & 1 & & 9 & \\
\hline Neurosyphilis & 16 & & & 1 & & 1 & & 4 & & 4 & & 6 & \\
\hline
\end{tabular}


latent syphilis, could be due solely to this infection. However, the results of exhaustive investigations with particular reference to autoimmune diseases) showed that this was so.

An illness other than syphilis which could be responsible for a persistently raised ESR was found in one case only. This was a man with early latent syphilis who had an ESR of $36 \mathrm{~mm}$ before treatment started. After treatment the ESR was 56, 50, and $48 \mathrm{~mm}$ on successive days and then fluctuated between 36 and $40 \mathrm{~mm}$ during the next 3 weeks. No clinical signs of disease were found on reexamination, but the chest radiograph revealed early tubercular infiltration of the upper lobe of the right lung.

\section{Discussion}

The manner in which the ESR is affected in clinically active syphilis could well have been anticipated, as could the increase in the ESR in the Herxheimer and occult Herxheimer reactions. The frequency with which the ESR is raised in latent syphilis was unexpected, particularly in late latent syphilis, where it is generally accepted that in 60 to 70 per cent. of cases the condition will remain latent in the absence of treatment (Stokes, Beerman, and Ingraham, 1945). The time taken for the ESR to return to normal after treatment in late syphilis, especially cardiovascular syphilis, was also unexpected, and is difficult to explain. Equally unexpected and difficult to explain, was the late rise in the ESR although one wondered if this was due to a reaction in the muscles to repeated penicillin injections.

That the ESR can be normal before treatment and raised very soon after treatment is started, obviously detracts markedly from any value the ESR might have in the pretreatment assessment of cases of syphilis, while its value after treatment is equally limited by the fact that its return to normal is no more indicative of cure than the healing of visible lesions. Indeed, only in the follow-up of late syphilis and particularly in that of cardiovascular syphilis, is the ESR helpful. Here, with adequate treatment, the ESR will show a marked decline long before the antibody titre alters and even in cardiovascular syphilis it will have returned to normal long before there is any noticeable fall in antibody titre.

A great many venereologists have taken part in this study. I am grateful to them and, in particular, to Dr. D. W. Higson, F.R.C.O.G., Dr. H. M. Fernando, and Dr. S. Chandramani.

\section{References}

FowlER, W. (1962) Paper read to MSSVD in April, 1962

HorRobin, D. F. (1968) 'Medical Physiology and Biochemistry', p. 290. Arnold, London

HytTen, F. E., and LIND, T. (1973) 'Diagnostic Indices in Pregnancy', p. 43. Documenta Geigy, Switzerland

Stokes, J. H., BeErman, H., and Ingraham, N. R. (1945)'Modern Clinical Syphilology', p. 443. Saunders, Philadelphia 